\title{
Política Industrial de Apoio ao Desenvolvimento da Indústria Brasileira de Semicondutores
}

\author{
Milton de Abreu Campanario ${ }^{1}$ \\ Marcello Muniz da Silva ${ }^{2}$ \\ Tiago Ribeiro Costa ${ }^{3}$
}

\section{Resumo}

A conquista da estabilidade macroeconômica tende a aumentar a discussão em torno de formas de intervenção nos planos microeconômico e setorial. A Política Industrial, Tecnológica e de Comércio Exterior (PITCE), lançada no início de 2004, sinalizou nessa direção, elegendo quatro setores considerados prioritários: fármacos, bens de capital, software e semicondutores. O presente artigo procura analisar a indústria de semicondutores nos contextos nacional e internacional e focaliza o papel da política industrial seletiva na dinamização de seu desenvolvimento. A partir da caracterização dessa indústria, é feito um benchmarking das políticas adotadas pela Coreia do Sul - país que apresentou, em certas fases de seu desenvolvimento industrial, características semelhantes ao brasileiro, mas que despontou como grande produtor e exportador de tecnologia de ponta. O texto indica que as políticas orientadas ao desenvolvimento da indústria de semicondutores, na PITCE, geram condições para a maturidade do setor. Contudo, essa maturidade enfatiza a fase de "imitação" (ligada ao processo de engenharia reversa) e de internalização (por meio do incremento dos processos de aprendizado e produção interna), mas pouca ênfase seria alcançada na fase de criação (obtenção de tecnologia própria) e de desenvolvimento de tecnologia nacional. Com esses percalços, em 2008, o governo atrelou o padrão da TV Digital (High Definition TV - HDT) à construção de uma fábrica de semicondutores no Brasil, buscando uma saída para implantar tal indústria por uma empresa transnacional.

Palavras-chave: Política Industrial. Tecnologia, Complexo Eletrônico. Semicondutores, PITCE.

\footnotetext{
Pós-Doutor pela International Development Center of Japan. Professor e Coordenador do Programa de Pós-Graduação em Administração da Universidade Nove de Julho - UNINOVE e Professor de Ciências Econômicas da Universidade de São Paulo - USP. Endereço: Av. Francisco Matarazzo 6122 Prédio C, Água Branca, CEP 05001-100 -São Paulo, SP. E-mail: campanario@uninove.br.

${ }^{2}$ Mestrado em Engenharia Naval e Oceânica pela POLI/USP. Professor do Programa de Pós-Graduação em Administração da UNINOVE, Doutorando em Engenharia pela Escola Politécnica da Universidade de São Paulo. Endereço: Av. Francisco Matarazzo 612 - Prédio C, Água Branca, CEP 05001-100 -São Paulo, SP. E-mail: marcello@ipt.br.

${ }^{3}$ Bacharel em Ciências Econômicas pela Universidade de São Paulo e Pós-graduado pelo Instituto de Pesquisas Tecnológicas - IPT. Endereço: Av. Francisco Matarazzo 612 - Prédio CÁgua Branca CEP 05001-100 - Sao Paulo, SP. E-mail: tiago@ipt.br. Artigo recebido em: 30/10/2006. Aceito em: 04/05/2007. Membro do Corpo Editorial Científico responsável pelo processo editorial: João Nilo Linhares.
} 


\section{Introdução}

A rápida e irresistível difusão dos equipamentos eletrônicos deu-se em meio à constante substituição e incremento desses aparelhos com uma intensidade tecnológica e leque de aplicações cada vez maior. Certamente aqui está presente a "destruição criadora" identificada por Schumpeter (1982), acompanhada da substituição e consequente desaparecimento de inúmeros equipamentos analógicos. Verifica-se a crescente participação nos equipamentos eletrônicos de um tipo especial de componente: os semicondutores. Por sua grande capacidade de armazenamento e velocidade de processamento, esses superam amplamente outros tipos de componentes em termos tecnológicos. Em meio a um intenso debate sobre o futuro dos sistemas eletrônicos nos anos 1960 e 1970, Gordon Moore, então presidente da Intel, criou o que seria conhecido mundialmente como Lei de Moore: a cada 18 meses a capacidade de processamento dos semicondutores seria dobrada. De fato, até o momento, a Lei de Moore permanece como um dos maiores dogmas da indústria, pois a realidade tem se comportado exatamente como o previsto.

O resultado imediato da crescente necessidade de incorporação de equipamentos eletrônicos nos diversos equipamentos é o impacto de mudanças na estrutura industrial - que no último quartel do Século XX caminhou em direção ao paradigma eletroeletrônico. Além das indústrias de informática e telecomunicações, que utilizam componentes eletrônicos em larga escala, outras, apesar de características distintas - como as indústrias automotiva e agropecuária -, devido à versatilidade de seu uso, incorporam esses componentes em diversos de seus produtos e/ou estrutura de produção. Em vista disso, o comércio mundial de semicondutores está em contínua expansão, sendo que seu mercado mais dinâmico, o de circuitos integrados, atingiu US\$ $\$ 248.6$ bilhões em 2008, de acordo com os dados da Semiconductor Industry Association - SIA (2009).

A viabilidade da produção de componentes eletrônicos, em especial os semicondutores, como estratégica industrial brasileira está presente desde 2004 com a Política Industrial, Tecnológica e de Comércio Exterior - PITCE. $\mathrm{O}$ argumento é que esta produção doméstica, mesmo que com tecnologia estrangeira, amplia a competitividade da indústria instalada, possibilita o desenvolvimento de novas tecnologias, gera conhecimento e inovação para 
todo o complexo eletrônico ${ }^{4}$, e diminui a dependência externa, haja vista o crescente déficit na balança comercial do complexo eletrônico (TAVARES, 2001; SICSÚ, 2002).

O caráter protecionista do modelo de substituição de importações, vigente entre os anos 1930 e 1980, fez a indústria nacional operar com baixa produtividade e tecnologia mais atrasada (NOGUEIRA; MEDEIROS; PEIXE, 2005). Com a abertura comercial dos anos 90, intensificou-se a defesa da inserção do país numa estrutura industrial mais competitiva frente ao mercado mundial (BONELLI, 1996). As doutrinas liberalizantes, aliadas à política de privatizações, em meio ao choque tecnológico trazido pela microeletrônica, sustentavam que o livre funcionamento dos mercados atrairia investimentos maciços, com consequente transferência de tecnologia, desenvolvimento $e$ reestruturação do parque produtivo nacional. De fato, observou-se avanço em diversas áreas, como o desenvolvimento do setor de telecomunicações, que teve um grande crescimento nas taxas de digitalização e universalização ${ }^{5}$. Entretanto, as políticas liberalizantes não foram suficientes para impulsionar a inovação de forma mais generalizada - haja vista o salto na importação de bens com alto conteúdo de tecnologia embarcada. Mais especificamente, não foi criado um ambiente produtivo $e$ institucional favorável à consolidação de um Sistema Nacional de Inovação (SNI), ${ }^{6}$ o que fez com que, apesar da conquista da estabilização macroeconômica, o país continuasse na dependência externa da aquisição de diversos insumos e tecnologias de produto e processo.

O Brasil apresenta um saldo total da balança comercial positivo a partir do início deste século. A responsabilidade desse fato é atribuída principalmente ao bom desempenho do setor agropecuário, e, em menor escala, aos setores intensivos em trabalho e de baixa intensidade tecnológica. O processo de abertura econômica do início dos anos 90 provocou um aumento da participação dos segmentos de média e alta intensidade tecnológica nas exportações. Entretanto, o aumento das importações nesses segmentos ocorreu de forma mais intensa, justificando o grande déficit comercial do período, como apresentado no Quadro 1.

\footnotetext{
${ }^{4} \mathrm{O}$ complexo eletrônico engloba setores de mesma base tecnológica, a microeletrônica. Geralmente são considerados como formadores do complexo eletrônico os setores de eletrônica de consumo, de informática, de equipamentos de telecomunicação e automação e de componentes eletrônicos. ${ }^{5}$ Para dados, consultar o relatório da Anatel no site <http://www.anatel.gov.br $>$.

${ }^{6}$ A Organização para a Cooperação e Desenvolvimento Econômico - OCDE define o Sistema Nacional de Inovação como uma interação de instituições públicas e privadas, cujas ações modificam e difundem novas tecnologias, visando à produção e ao desenvolvimento de C\&T dentro da fronteira nacional.
} 


\begin{tabular}{|c|c|c|c|c|c|c|c|}
\hline \multirow[b]{2}{*}{ Setores } & \multicolumn{7}{|c|}{ Participação em termos do valor médio do período. } \\
\hline & \%199697 & \%1998999 & $\% 200001$ & $\% 200203$ & $\% 200405$ & $\% 200607$ & 2008 (**) \\
\hline $\begin{array}{l}\text { Indústria de alta } \\
\text { tecnologia (I) }\end{array}$ & 19,98 & 22,40 & 25,13 & 21,86 & 22,91 & 22,09 & 19,31 \\
\hline $\begin{array}{l}\text { Indústria de média- } \\
\text { alta tecnologia (II) }\end{array}$ & 40,33 & 43,09 & 39,91 & 41,71 & 38,99 & 37,57 & 40,01 \\
\hline $\begin{array}{l}\text { Subtotal: Indústria } \\
\text { de alta e média-alta } \\
\text { tecnologia (I+II) }\end{array}$ & 60,31 & 65,50 & 65,04 & 63,57 & 61,90 & 59,65 & 59,31 \\
\hline $\begin{array}{l}\text { Indústria de média- } \\
\text { baixa tecnologia (III) }\end{array}$ & 13,10 & 13,18 & 15,30 & 14,10 & 14,02 & 15,99 & 16,87 \\
\hline $\begin{array}{l}\text { Indústria de baixa } \\
\text { tecnologia (IV) }\end{array}$ & 12,61 & 10,48 & 7,91 & 7,30 & 6,45 & 6,87 & 6,49 \\
\hline $\begin{array}{l}\text { Produtos não } \\
\text { industriais }(\mathrm{V})\end{array}$ & 13,98 & 10,84 & 11,75 & 15,03 & 17,63 & 17,48 & 17,33 \\
\hline $\begin{array}{l}\text { Total }(I+I I+I I I+ \\
\text { VI }+ \text { V) }\end{array}$ & 100,00 & 100,00 & 100,00 & 100,00 & 100,00 & 100,00 & 100,00 \\
\hline
\end{tabular}

Quadro 1: Brasil - Comércio Exterior por intensidade tecnológica (média da participação em \%). Fonte: Elaborado a partir de dados obtidos junto à Secretaria de Comércio Exterior SECEX.

(*) Classificação extraída de: OECD, Directorate for Science, Technology and Industry, STAN Indicators, 2003. (**) Até a finalização desse estudo não se dispunha de estimativas para o ano de 2009.

Em torno dessas evidências, a discussão acerca da inserção do país nos setores de maior intensidade tecnológica é retomada com grande relevância. Sinalizando nessa direção, o governo lançou, em março de 2004, a PITCE. Almejando corrigir os desequilíbrios provocados pela falta de dinâmica desses setores, a PITCE elegeu quatro segmentos considerados prioritários e de alto conteúdo estratégico: fármacos, software, bens de capital e semicondutores. Por ser considerado um setor chave no desenvolvimento industrial, a indústria de semicondutores torna-se um objeto de grande relevância para investigação. A presente investigação procura, por meio da revisão da literatura nacional e internacional, enfatizar ao papel da política industrial e tecnológica como ponto fundamental para o desenvolvimento dos setores de alta intensidade tecnológica, e sumarizar alguns desafios.

Para isso, também é feito um estudo sumário acerca das políticas adotadas na Coreia do Sul, que apresentou, durante o pós-guerra, uma eco- 
nomia com características semelhantes à brasileira, mas que conseguiu atingir um padrão moderno de desenvolvimento industrial com grande peso do setor eletroeletrônico. Tendo em vista esse benchmark, o artigo procura apresentar evidência quanto ao papel da política industrial para o desenvolvimento desse setor. Ainda nesse contexto, identifica-se o caráter da PITCE na criação de um ambiente favorável ao SNI e no desenvolvimento da indústria microeletrônica nacional. Finalmente um destaque é feito à estratégia mais recente de associar a construção de um parque de semicondutores no Brasil à escolha do padrão de TV digital e a incentivos criados pelo Banco Nacional de Desenvolvimento Econômico e Social - BNDES.

$\mathrm{O}$ artigo é divido em cinco seções, contando com esta introdução. $\mathrm{Na}$ Seção 2 são demonstradas as características do setor de semicondutores, assim como o funcionamento do processo produtivo. A Seção 3 discute os aspectos de mercado no Brasil e no mundo, dando ênfase para a atual estrutura de mercado brasileira e os desequilíbrios da balança comercial. Na Seção 4 é analisada a questão da política industrial dos governos como forma de dinamizar o desenvolvimento industrial dos países. Nessa seção inclui-se uma caracterização da PITCE e de políticas aplicadas na Coreia do Sul. Por fim, a última seção traça considerações finais e uma comparação entre os programas nacionais e a experiência estrangeira.

\section{Caracterização, Processo Produtivo e Intensidade Tecnológica da Indústria Microeletrônica}

\subsection{Caracterização de Semicondutores e sua Tecnologia Produtiva}

Semicondutores são materiais, como silício, zinco e germânio, cuja resistividade elétrica é caracterizada por situar-se entre os materiais bons condutores e os isolantes. Um elemento dessa natureza pode atuar como um condutor ou não-condutor, dependendo da polaridade da carga elétrica aplicada a ele. $\mathrm{O}$ motivo de o silício ser amplamente utilizado é a facilidade com que é encontrado na natureza. Os chamados dispositivos semicondutores são componentes constituídos por silício, contendo circuitos miniaturizados capazes de armazenar e manipular informações na forma de impulsos elétricos. 
Segundo Swart (2005), a utilização dos semicondutores teve início a partir das limitações das antigas válvulas, que apresentavam diversos problemas como reduzida durabilidade, grandes dimensões, alto consumo de energia e baixa eficiência computacional. Essas limitações motivaram laboratórios, como a Bell Labs, a investir em pesquisas para a substituição das válvulas por dispositivos mais eficientes. ${ }^{7}$ Não demorou muito para que as descobertas e melhorias técnicas (feitas a partir de um melhor conhecimento das propriedades materiais semicondutores) substituíssem as válvulas pelos dispositivos semicondutores, chamados de transistores, levando em 1947 ao surgimento do primeiro transistor de germânio utilizado em um circuito amplificador.

Os transistores são o principal componente dos circuitos integrados ou microchips, sendo que é a interligação desses componentes a responsável por dotá-lo de um processamento voltado a alguma aplicação. A utilização dos transistores em larga escala permitiu a criação de circuitos eletrônicos extremamente complexos (microprocessadores e dispositivos de memória são os mais conhecidos), sendo que atualmente um único microchip é capaz de armazenar milhões de transistores. Dessa forma, o papel principal dos dispositivos semicondutores no desenvolvimento dos diversos elos do complexo eletrônico é a miniaturização dos componentes eletrônicos (MELO, RIOS; GUTIERREZ, 2001). De maneira geral, tornou-se comum chamar os circuitos integrados de semicondutores. Um dos critérios de classificação desses componentes é o nível de complexidade de sua estrutura interna. O Quadro 2 descreve os principais tipos de semicondutores existentes.

\begin{tabular}{|ll|}
\hline \multicolumn{1}{|c|}{ Tipo } & \multicolumn{1}{c|}{ Características } \\
\hline Discretos & $\begin{array}{l}\text { Estrutura bastante simples, capazes de executar uma única função (resistores, } \\
\text { capacitores, etc) }\end{array}$ \\
\hline Integrados & $\begin{array}{l}\text { Estrutura complexa, capazes de executar múltiplas funções (microchips). São os } \\
\text { componentes que possuem o maior valor adicionado. }\end{array}$ \\
\hline Optoeletrônicos & Componentes como os usados em telecomunicações. \\
\hline Sensores & Dispositivos de medição \\
\hline & \multicolumn{1}{c|}{ Principais tipos de circuitos integrados } \\
\hline Analógicos & Componentes que usam sinais analógicos como os amplificadores \\
\hline Micrológicos & $\begin{array}{l}\text { Componentes como os microprocessadores, microcontroladores e microperiféricos, } \\
\text { incluindo também dispositivos programáveis lógicos como os CPLDs (Complex } \\
\text { Programmable Logic Device) e FPGAs (Field-Programmable Gate Array) }\end{array}$ \\
\hline Memórias & Componentes para armazenamento de dados \\
\hline $\begin{array}{l}\text { ASIC (Application Specific } \\
\text { Integrated Circuit) }\end{array}$ & CIs de aplicações específicas \\
\hline
\end{tabular}

Quadro 2: Principais tipos de Semicondutores.

Fonte: Construído a partir de informações de Amato Neto (2005) e Melo, Rios e Gutierrez (2002).

${ }^{7}$ É interessante notar que o modelo de desenvolvimento tecnológico nesse período se aproxima do "science push", quando a pesquisa era de certa forma orientada pela curiosidade. Com a popularização dos computadores, com os avanços das comunicações e com novas demandas de mercado, o modelo de desenvolvimento tecnológico passou a funcionar no esquema "market-pull", em que o mercado dita os investimentos em inovações. 


\subsection{Processo Produtivo}

Seguindo Amato Neto (2002), pode-se descrever o processo de produção de um componente semicondutor em três etapas: Projeto (design); Fabricação (front-end); e Encapsulamento e Teste (back-end). A intensidade de conhecimentos, investimentos exigidos e o valor agregado ao produto variam em cada uma dessas etapas.

Projeto (design): é nessa fase que os componentes e suas interligações e posições dentro do dispositivo semicondutor são definidos. Apesar do investimento necessário para a construção de uma Design $\mathrm{House}^{8}$ ser bem inferior ao de uma Foundry ${ }^{9}$, essa etapa é extremamente importante, pois define a funcionalidade do componente. Além das considerações acerca da capacidade técnica e da eficiência do dispositivo projetado, certamente é necessária uma análise de viabilidade econômica a respeito do custo de desenvolvimento e das expectativas de mercado.

Fabricação (front-end): nesse momento, o projeto da fase anterior será transformado em algo concreto: as pastilhas de wafer. O processo de fabricação de um circuito integrado é extremamente complexo ${ }^{10}$, necessitando de investimentos que podem chegar a US $\$ 2$ bilhões para a montagem de uma foundry de nível 3, o mais elevado. Essas são as fábricas de grande intensidade tecnológica e também de maior escala de produção, como as usadas na fabricação de microprocessadores. Aqui se percebe amplamente o efeito dos "sunk costs" 11 à medida que o investimento nessas fábricas só pode ser recuperado com larga escala de produção e em um curto período de tempo. As foundries de nível 1 e 2 requerem um padrão de investimento menor, operando em escalas mais reduzidas; no geral são dedicadas a segmentos de mercado mais especializados, como o automotivo, ou mesmo nichos de mercado, como os dispositivos utilizados em alguns aparelhos eletrônicos.

Encapsulamento e testes (back-end): essa etapa consiste na separação das pastilhas de wafer, com consequente encapsulamento e teste de funcionalidade para estarem aptas para serem usadas em placas de circuito eletrônico como as dos computadores, DVD players, etc.

\footnotetext{
${ }^{8}$ Empresas destinadas ao projeto de circuitos integrados.

${ }^{9}$ Refere-se à fundição, local onde ocorre a fabricação dos semicondutores.

${ }^{10}$ Para maiores detalhes, ver Amato Neto (2004); e Melo et al. (2001).

${ }^{11}$ Sunk costs são custos fixos que não podem ser recuperados. Os produtos que exigem constante inovação tecnológica possuem relevantes "sunk costs", principalmente na forma de $\mathrm{P} \& \mathrm{D}$ e patentes. Esses custos podem representar significantes barreiras à entrada de novos sujeitos no mercado, à medida que podem inibir potenciais novos entrantes, principalmente devido ao alto custo de uma entrada mal sucedida.
} 


\subsection{Intensidade Tecnológica e Valor dos CIs (Circuitos Integrados)}

Os circuitos integrados - CIs são considerados os principais tipos de semicondutores, tanto pelo seu grau de complexidade e utilidade, quanto pelo valor agregado ao componente. Dispositivos como os microprocessadores e memórias concentram um maior dinamismo tecnológico, embutindo uma capacidade cada vez maior de processamento e armazenamento (AMATO NETO, 2004; AMATO NETO et al., 2002; MELO, RIOS, GUTIERREZ, 2001). Isso ocorre porque são componentes essenciais para o bom desempenho de diversos equipamentos, entre eles, os computadores. A permanente necessidade de novos softwares, de novos dispositivos para automação industrial e da sempre crescente demanda por aparelhos eletrônicos mais modernos estimula a indústria de Cls para um constante processo de inovação, buscando novas soluções, tecnologias e equipamentos. A existência de competição com outros agentes no mercado e as garantias de direito de propriedade intelectual aumentam o valor e os lucros dos produtos das firmas que introduzem inovações tecnológicas (NOGUEIRA; MEDEIROS; PEIXE, 2005). A Figura 1 ajuda a elucidar os fatos mencionados.
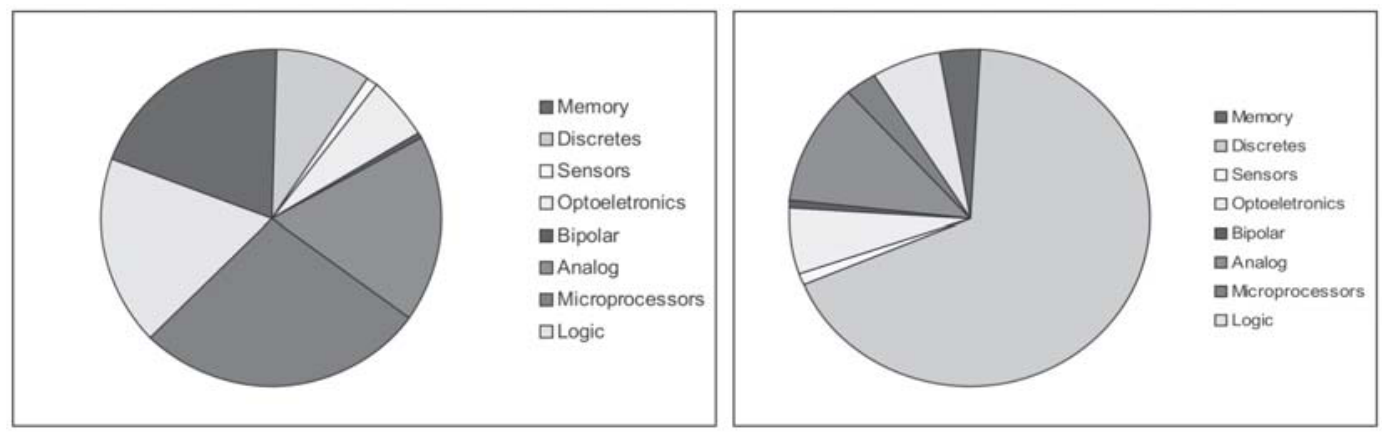

Figura 1: Participação em valor e no volume total de unidades por tipo de semicondutor 2001.

Fonte: Extraída e adaptada de Turley (2003).

O lado esquerdo representa a participação por tipo de semicondutor no valor total transacionado, enquanto o lado direito representa a estrutura de participação no total de unidades comercializadas. Os componentes discretos representam uma enorme participação no total de unidades comercializadas, mas apenas uma pequena participação no valor total das transações. Componentes como microprocessadores apresentam uma alta participação no valor total transacionado e apenas uma pequena parcela no 
total de unidades comercializadas. De maneira geral, a participação no total do valor é diretamente proporcional à intensidade tecnológica inerente em cada tipo de componente.

Isso acontece porque os componentes discretos são facilmente reproduzidos, requerem uma escala não muito alta para viabilizar a produção e a demanda é alta e dinâmica, incentivando o aparecimento de diversos participantes do lado da oferta. Além disso, os investimentos e custos necessários para fabricação, em especial os custos de aquisição de tecnologia, são relativamente baixos, e os produtos resultantes são praticamente homogêneos, fazendo com que esse se aproxime de um mercado perfeitamente competitivo, tornando as empresas ofertantes "price takers" (VARIAN, 2002). Já os componentes micrológicos requerem uma escala bem maior para a viabilidade da produção, o que significa altos custos fixos e também custos irrecuperáveis, ou "sunk costs", culminando com poucas empresas participantes. Vale ressaltar que esse é um mercado em que não existem produtos substitutos, e que fatores como inovação, patente e marketing produzem grande diferencial de produto e levam a maiores possibilidades de ganhos de monopólio. (VARIAN, 2002; NOGUEIRA; MEDEIROS; PEIXE, 2005). De acordo com a visão schumpeteriana, as firmas inovam porque procuram maior rentabilidade, uma vez que uma nova tecnologia produz algumas vantagens para o inovador: redução de custos (inovação de processo) e monopólio temporário (inovação de produto), devido às patentes ou atraso tecnológico dos competidores. Ao adotar novas tecnologias de produto ou processo, a firma pode atuar no mercado com um preço acima de um mercado competitivo. Esses são fatores importantes para o estudo da atual estrutura de mercado.

\section{Estrutura de Mercado}

Como já foi dito, o mercado de semicondutores está em franca expansão, apesar de períodos de recessão, como em 2001 e 2008. A taxa de crescimento vem atingindo patamares de $12 \%$ ao ano (SIA, 2009). A principal característica desse mercado é que a produção mundial de dispositivos semicondutores está concentrada em poucas regiões do mundo (BYUN, 1994). A Figura 2 dá indícios acerca da reestruturação da produção mundial de semicondutores ao longo das décadas de 80 e 90, principalmente pela ascensão da região do Pacífico Asiático. Como será discutido na Seção 4.2, 
as políticas adotadas em países asiáticos, que, em período anterior à década de 80 , detinham apenas percentual inferior a $5 \%$ da produção mundial, elevaram a participação da região, na década de 90 , para cerca de $30 \%$ e continuam a crescer (SAI, 2009). Esse aumento é liderado principalmente pela produção de memórias, sendo que somente a Coréia do Sul representa em torno de $25 \%$ da oferta mundial

Ao longo dos últimos anos verifica-se uma oscilação nos preços dos componentes. É interessante observar que a quantidade demandada de semicondutores tem demonstrado ser crescente e com oscilações amenas, o que faz as mudanças nos preços estarem mais relacionadas com variações na quantidade ofertada. A oferta de semicondutores depende da capacidade instalada das indústrias. No caso das memórias, as variações de preços foram ocasionadas pela grande inserção de empresas asiáticas, que transformaram os dispositivos de memória em "commodities". As expectativas de aumento da demanda para a segunda metade da década de 90 foram maiores do que a verdadeiramente ocorrida, o que fez com que as empresas investissem na ampliação da capacidade instalada. É interessante notar que, mesmo com a entrada de novas empresas, a oferta de semicondutores continua sendo ditada por um número relativamente pequeno de produtores.

A oferta de dispositivos semicondutores é relativamente rígida no curto prazo, variando apenas por algum excesso de ociosidade. No longo prazo, a oferta tem uma tendência crescente, mas em saltos. Isso acontece porque o investimento na ampliação e/ou criação de novas fábricas só se justifica com grandes expectativas de crescimento da demanda. Quando essas expectativas são maiores que a realidade, há a tendência de um aumento e de formação de um excesso de capacidade instalada, acarretando aumento na quantidade ofertada e provocando queda de preços. Continuando a tendência de crescimento da demanda, os preços tendem a se ajustar novamente até nova ampliação na quantidade ofertada. Esse fato tem acontecido com alguns produtos mais "comoditizados" do mercado de informática, como as memórias e alguns outros dispositivos utilizados em eletrônica de consumo e informática.

No caso de produtos como microprocessadores, o número de agentes do lado da oferta se reduz ainda mais. Tomando-se o mercado mais dinâmico, o de computadores, a oferta mundial de microprocessadores pode ser reduzida pela atuação de poucas empresas. Nesse caso, a quantidade ofertada vai depender do mercado a que o produto se destina. A rigor, essas empresas vão maximizar o retorno por meio de diferenciação de produto. A dife- 


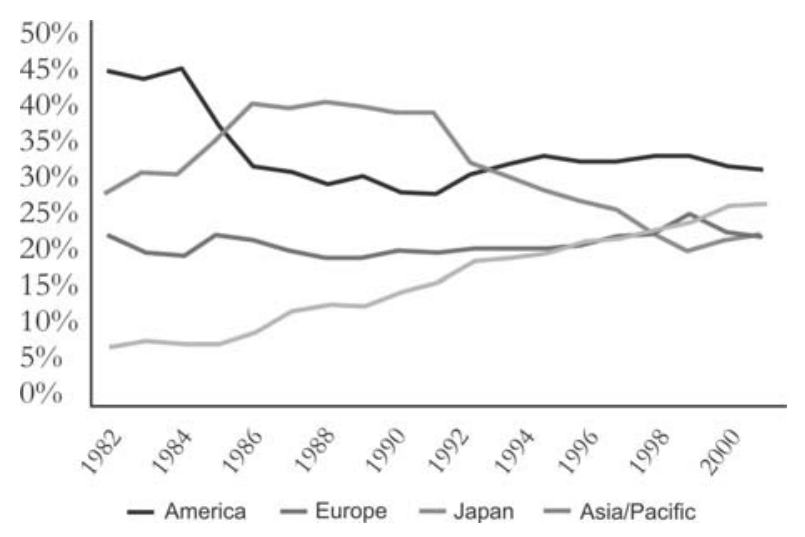

Figura 2: Participação na oferta mundial das diversas regiões do mundo. Fonte: Extraída e adaptada de Turley (2003).

renciação de produto se dará por meio de ganhos de exclusividade de mercado durante um "gap" tecnológico". A diferenciação de mercado se dará pela oportunidade de apropriação de uma parcela maior do excedente do consumidor, por meio de uma política de preços "regressiva" e ou segmentação do mercado (onde é possível realizar discriminação de preços). ${ }^{13}$

Ao contrário do que ocorre do lado da oferta, o lado da demanda é composto pela participação de inúmeros agentes.

Como conhecido, o rol de utilização de semicondutores é imenso, podendo ser utilizados tanto em um supercomputador como em um simples relógio de pulso. Apesar da grande possibilidade de aplicações, a demanda por esses dispositivos está fortemente concentrada nas indústrias de computadores e comunicações, que concentram cerca de $65 \%$ do mercado (SIA, 2009). De fato, em um computador está concentrada a maior parcela de valor dos semicondutores (processadores e memórias), o que faz com que a participação dos computadores na utilização de semicondutores chegue a quase metade da produção total. Por sua vez, a aplicação em comunicações vem se tornando muito comum ao longo da última década, com a massificação da telefonia celular (ligada também à customização em massa). Esse fato justifica o crescente aumento da participação de componentes de telecomunicações que dobrou em menos de dez anos.

\footnotetext{
${ }^{12}$ Quando um produto apresenta vantagens tecnológicas sobre os demais durante um curto período de tempo

${ }^{13}$ Os produtos vão sendo lançados no mercado com redução de preços ao longo do tempo, de forma a atingir os variados grupos de consumidores.
} 
Outro setor que demonstra ter um grande potencial de crescimento na demanda por semicondutores é o automotivo. Os carros modernos necessitam cada vez mais da inserção de componentes eletrônicos por diversas questões, como segurança, mudanças mecânicas e entretenimento. Os projetos mais audaciosos buscam incluir nos automóveis diversos sensores, computadores de bordo, GPS, além dos mais variados mecanismos de ajuste automático. As indústrias também são grande demandante de semicondutores. Os processos de produção estão cada vez mais necessitando de automação controlada por sistemas e aparelhos informatizados. A grande expressão da presença dos dispositivos semicondutores nas indústrias são as máquinas robotizadas. A rigor, essas máquinas são mecanismos repletos de motores e sensores controlados por diversos microprocessadores e microcontroladores (TURLEY, 2003). Essa grande difusão e aumento da importância dos diversos tipos de semicondutores abrem espaço para uma reflexão da natureza estratégica dessa indústria em termos macro, setoriais e microeconômicos.

\subsection{Mercado de Semicondutores no Brasil}

Seguindo a caracterização de países industrializados, o mercado brasileiro de semicondutores também apresenta grandes proporções. O faturamento do complexo eletrônico à época de lançamento da PITCE estava em torno de US $\$ 25$ bilhões, entretanto, a quase totalidade desse valor é de importações. Muito pouco se produz no Brasil em termos de equipamentos eletrônicos, e, considerada somente a produção de semicondutores, o número se reduz apenas à produção de componentes discretos. No caso de componentes integrados, não existem indústrias detentoras de todo o ciclo de produção (TAVARES, 2001). De maneira geral, a produção de eletroeletrônicos está concentrada na Zona Franca de Manaus (cerca de 25\%), mas, embora a produção possa parecer um número expressivo, se trata basicamente de montagem de kits importados, contribuindo a indústria nacional com uma pequena parte do valor agregado aos diversos produtos. A crescente difusão (apontada acima) e os aspectos da produção local se refletem diretamente no padrão de comércio desse tipo de produto (Quadro 3) - fato que justifica esforços da coletividade na introdução de todos os elos da cadeia dessa indústria. 
O Quadro 3 exibe um bom panorama do complexo eletrônico brasileiro em períodos anteriores e posteriores ao lançamento da PITCE, indicando uma preocupante situação dos diferentes segmentos em termos dos déficits em Transações Correntes. Em suma: verifica-se: (i) déficits sistematicamente crescentes em componentes elétricos e eletrônicos que atingem mais de US\$ 14 bilhões em 2008; (ii) sensível aumento nos déficits em automação industrial acompanhando o crescimento do PIB; (iii) superávits no setor de telecomunicações a partir de 2002 e reversão dessa tendência em 2008; (iv) déficits crescentes em informática explicados pelo aumento da demanda em razão da apreciação cambial e expansão do crédito no varejo para esse tipo de produto; (v) superávits modestos em geração, transmissão e distribuição de equipamentos de energia elétrica relacionados reestruturação do setor e ao aquecimento do mercado após a crise do "apagão"; (vi) tendência de crescimento do déficit em unidades domésticas que vinham apresentando superávits até 2006; e (vi) tendência a manutenção de déficits em material elétrico e equipamentos industriais que vem dando sinais de deterioração na tendência.

Vale ressaltar que entre o período compreendido entre 2003 e 2007 foi favorável às exportações. Para efeito ilustrativo, as importações de petróleo bruto (maior valor em importações em 2003) foram de aproximadamente US \$ 3,7 bilhões; as exportações de todo o complexo da soja brasileiro e de papel e celulose (dois dos principais produtos de exportação no ano de 2003) foram respectivamente de US\$ 8,1 bilhões e US\$ 2,8 bilhões. Mais recentemente o país vem apresentando superávits na conta petróleo devido aos resultados do processo de reestruturação no setor (com ampliação no volume de investimentos e introdução de inovações) que teve como base uma clara visão quanto à natureza estratégica do setor. Especificamente, os semicondutores aparecem na liderança dos produtos eletroeletrônicos importados - representando, em média, mais de $60 \%$ dos componentes importados e cerca de $30 \%$ de todo o complexo eletrônico com forte tendência de crescimento nesses percentuais, tal qual os dados acima apontam.

Esses dados demonstram claramente o caráter estrutural do déficit da balança comercial em semicondutores. Nesse sentido, variações na demanda interna por semicondutores refletem em impacto de igual proporção nas importações. Outra ressalva: os dados mencionados consideram somente o mercado formal. 


\begin{tabular}{|c|c|c|c|c|c|c|}
\hline \multicolumn{7}{|c|}{ Importações de produtos eletrônicos por categoria (valores em milhóes de US\$ e } \\
\hline Categoria & \multicolumn{2}{|c|}{2001} & \multicolumn{2}{|c|}{2002} & \multicolumn{2}{|c|}{2003} \\
\hline Automação industrial (1) & 965,8 & $7 \%$ & 776,1 & $8 \%$ & 707,8 & $7 \%$ \\
\hline Componentes elétricos e eletrônicos (2) & 6228,8 & $46 \%$ & 5213,1 & $51 \%$ & 5734,6 & $57 \%$ \\
\hline Equipamentos industriais & 1580,3 & $12 \%$ & 1795,4 & $17 \%$ & 1287,1 & $13 \%$ \\
\hline $\begin{array}{l}\text { Geração, transmissão e distribuição } \\
\text { de energia elétrica }\end{array}$ & 337,5 & $3 \%$ & 279,0 & $3 \%$ & 221,1 & $2 \%$ \\
\hline Informática & 1042,7 & $8 \%$ & 736,9 & $7 \%$ & 656,8 & $7 \%$ \\
\hline Material elétrico de instalações & 593,4 & $4 \%$ & 436,9 & $4 \%$ & 449,4 & $4 \%$ \\
\hline Telecomunicações & 2340,1 & $17 \%$ & 707,1 & $7 \%$ & 605,0 & $6 \%$ \\
\hline Unidades domésticas (3) & 400,0 & $3 \%$ & 350,0 & $3 \%$ & 386,0 & $4 \%$ \\
\hline Total & 13488,6 & $100 \%$ & 10294,5 & $100 \%$ & 10047,8 & $100 \%$ \\
\hline \multicolumn{7}{|c|}{ Exportações de produtos eletrônicos por categoria (valores em milhóes de US\$ e } \\
\hline Categoria & \multicolumn{2}{|c|}{2001} & \multicolumn{2}{|c|}{2002} & \multicolumn{2}{|c|}{2003} \\
\hline Automação industrial (1) & 74,2 & $2 \%$ & 66,7 & $2 \%$ & 76,5 & $2 \%$ \\
\hline Componentes elétricos e eletrônicos (2) & 1636,8 & $35 \%$ & 1716,2 & $39 \%$ & 1760 & $37 \%$ \\
\hline Equipamentos industriais & 351,6 & $7 \%$ & 297,6 & $7 \%$ & 362,8 & $8 \%$ \\
\hline $\begin{array}{l}\text { Geração, transmissão e distribuição } \\
\text { de energia elétrica }\end{array}$ & 204,9 & $4 \%$ & 170,5 & $4 \%$ & 165 & $3 \%$ \\
\hline Informática & 254,9 & $5 \%$ & 121,2 & $3 \%$ & 193,5 & $4 \%$ \\
\hline Material elétrico de instalações & 154,7 & $3 \%$ & 142,4 & $3 \%$ & 150,7 & $3 \%$ \\
\hline Telecomunicações & 1337,8 & $28 \%$ & 1343 & $30 \%$ & 1333,9 & $28 \%$ \\
\hline Unidades domésticas (3) & 716,7 & $15 \%$ & 557,7 & $13 \%$ & 728,7 & $15 \%$ \\
\hline Total & 4731,6 & $100 \%$ & 4415,3 & $100 \%$ & 4771,1 & $100 \%$ \\
\hline \multicolumn{7}{|c|}{ Saldo da Balança Comercial de produtos eletrônicos por categoria (valores em } \\
\hline Categoria & \multicolumn{2}{|c|}{2001} & \multicolumn{2}{|c|}{2002} & \multicolumn{2}{|c|}{2003} \\
\hline Automação industrial (1) & $-891,6$ & $10 \%$ & $-709,4$ & $12 \%$ & $-631,3$ & $12 \%$ \\
\hline Componentes elétricos e eletrônicos (2) & $-4592,0$ & $52 \%$ & $-3496,9$ & $59 \%$ & $-3974,6$ & $75 \%$ \\
\hline Equipamentos industriais & $-1228,7$ & $14 \%$ & $-1497,8$ & $25 \%$ & $-924,3$ & $18 \%$ \\
\hline $\begin{array}{l}\text { Geração, transmissão e distribuição } \\
\text { de energia elétrica }\end{array}$ & $-132,6$ & $2 \%$ & $-108,5$ & $2 \%$ & $-56,1$ & $1 \%$ \\
\hline Informática & $-787,8$ & $9 \%$ & $-615,7$ & $10 \%$ & $-463,3$ & $9 \%$ \\
\hline Material elétrico de instalações & $-438,7$ & $5 \%$ & $-294,5$ & $5 \%$ & $-298,7$ & $6 \%$ \\
\hline Telecomunicações & $-1002,3$ & $11 \%$ & 635,9 & $-11 \%$ & 728,9 & $-14 \%$ \\
\hline Unidades domésticas (3) & 316,7 & $-4 \%$ & 207,7 & $-4 \%$ & 342,7 & $-6 \%$ \\
\hline Total & $-8757,0$ & $100 \%$ & $-5879,2$ & $100 \%$ & $-5276,7$ & $100 \%$ \\
\hline
\end{tabular}

Quadro 3: Importação, exportações e Saldo da Balança Comercial do Complexo Eletrônico 2001/2008 - em US\$ milhões.

Fonte: Elaborado a partir de dados consolidados pela Associação Brasileira da Indústria Elétrica e Eletrônica - Abinee. 


\begin{tabular}{|c|c|c|c|c|c|c|c|c|c|}
\hline \multicolumn{10}{|c|}{ \% período) ${ }^{14}$. } \\
\hline \multicolumn{2}{|c|}{2004} & \multicolumn{2}{|c|}{2005} & \multicolumn{2}{|c|}{2006} & \multicolumn{2}{|c|}{2007} & \multicolumn{2}{|c|}{2008} \\
\hline 870,4 & $7 \%$ & 828,8 & $5 \%$ & 1325,6 & $7 \%$ & 1757,4 & $7 \%$ & 2275,8 & $7 \%$ \\
\hline 7825,8 & $62 \%$ & 9617,2 & $64 \%$ & 11909,8 & $60 \%$ & 13647,9 & $57 \%$ & 17824,0 & $56 \%$ \\
\hline 894,7 & $7 \%$ & 949,9 & $6 \%$ & 1518,5 & $8 \%$ & 1892,1 & $8 \%$ & 2805,8 & $9 \%$ \\
\hline 224,3 & $2 \%$ & 223,0 & $1 \%$ & 310,2 & $2 \%$ & 388,3 & $2 \%$ & 498,1 & $2 \%$ \\
\hline 778,1 & $6 \%$ & 1017,5 & $7 \%$ & 1399,7 & $7 \%$ & 1883,3 & $8 \%$ & 2242,3 & $7 \%$ \\
\hline 585,6 & $5 \%$ & 569,7 & $4 \%$ & 651,6 & $3 \%$ & 755,6 & $3 \%$ & 1043,9 & $3 \%$ \\
\hline 923,7 & $7 \%$ & 1093,5 & $7 \%$ & 1234,5 & $6 \%$ & 2020,9 & $8 \%$ & 3202,7 & $10 \%$ \\
\hline 564,7 & $4 \%$ & 835,5 & $6 \%$ & 1354,9 & $7 \%$ & 1707,5 & $7 \%$ & 2140,1 & $7 \%$ \\
\hline 12667,3 & $100 \%$ & 15135,1 & $100 \%$ & 19704,8 & $100 \%$ & 24053,0 & $100 \%$ & 32032,7 & $100 \%$ \\
\hline \multicolumn{10}{|c|}{ \% período). } \\
\hline \multicolumn{2}{|c|}{2004} & \multicolumn{2}{|c|}{2005} & \multicolumn{2}{|c|}{2006} & \multicolumn{2}{|c|}{2007} & \multicolumn{2}{|c|}{2008} \\
\hline 114,4 & $2 \%$ & 143,7 & $2 \%$ & 238,9 & $3 \%$ & 280,3 & $3 \%$ & 314,2 & $3 \%$ \\
\hline 1992,8 & $37 \%$ & 2286 & $29 \%$ & 2708,4 & $29 \%$ & 3151,1 & $34 \%$ & 3304,3 & $33 \%$ \\
\hline 475,9 & $9 \%$ & 640,4 & $8 \%$ & 917,8 & $10 \%$ & 1012,8 & $11 \%$ & 1141,2 & $12 \%$ \\
\hline 274,7 & $5 \%$ & 334,6 & $4 \%$ & 515,8 & $6 \%$ & 657,2 & $7 \%$ & 864,9 & $9 \%$ \\
\hline 263,3 & $5 \%$ & 387 & $5 \%$ & 411 & $4 \%$ & 337,8 & $4 \%$ & 312,6 & $3 \%$ \\
\hline 202,8 & $4 \%$ & 228,6 & $3 \%$ & 308,2 & $3 \%$ & 288,5 & $3 \%$ & 325,5 & $3 \%$ \\
\hline 1142 & $21 \%$ & 2832,3 & $36 \%$ & 3114,5 & $34 \%$ & 2491,5 & $27 \%$ & 2539,7 & $26 \%$ \\
\hline 878,4 & $16 \%$ & 914,4 & $12 \%$ & 1034,6 & $11 \%$ & 1080,7 & $12 \%$ & 1088,5 & $11 \%$ \\
\hline 5344,3 & $100 \%$ & 7767,0 & $100 \%$ & 9249,2 & $100 \%$ & 9299,9 & $100 \%$ & 9890,9 & $100 \%$ \\
\hline \multicolumn{10}{|c|}{ milhóes de US\$ e \% período). } \\
\hline \multicolumn{2}{|c|}{2004} & \multicolumn{2}{|c|}{2005} & \multicolumn{2}{|c|}{2006} & \multicolumn{2}{|c|}{2007} & \multicolumn{2}{|c|}{2008} \\
\hline$-756,0$ & $10 \%$ & $-685,1$ & $9 \%$ & $-1086,7$ & $10 \%$ & $-1477,1$ & $10 \%$ & $-1961,6$ & $9 \%$ \\
\hline$-5833,0$ & $80 \%$ & $-7331,2$ & $99 \%$ & $-9201,4$ & $88 \%$ & $-10496,8$ & $71 \%$ & $-14519,7$ & $66 \%$ \\
\hline$-418,8$ & $6 \%$ & $-309,5$ & $4 \%$ & $-600,7$ & $6 \%$ & $-879,3$ & $6 \%$ & $-1664,6$ & $8 \%$ \\
\hline 50,4 & $-1 \%$ & 111,6 & $-2 \%$ & 205,6 & $-2 \%$ & 268,9 & $-2 \%$ & 366,8 & $-2 \%$ \\
\hline$-514,8$ & $7 \%$ & $-630,5$ & $9 \%$ & $-988,7$ & $9 \%$ & $-1545,5$ & $10 \%$ & $-1929,7$ & $9 \%$ \\
\hline$-382,8$ & $5 \%$ & $-341,1$ & $5 \%$ & $-343,4$ & $3 \%$ & $-467,1$ & $3 \%$ & $-718,4$ & $3 \%$ \\
\hline 218,3 & $-3 \%$ & 1738,8 & $-24 \%$ & 1880,0 & $-18 \%$ & 470,6 & $-3 \%$ & $-663,0$ & $3 \%$ \\
\hline 313,7 & $-4 \%$ & 78,9 & $-1 \%$ & $-320,3$ & $3 \%$ & $-626,8$ & $4 \%$ & $-1051,6$ & $5 \%$ \\
\hline$-7323,0$ & $100 \%$ & $-7368,1$ & $100 \%$ & $-10455,6$ & $100 \%$ & $-14753,1$ & $100 \%$ & $-22141,8$ & $100 \%$ \\
\hline
\end{tabular}

Notas: (1) Inclui instrumentação e instrumentos eletromédicos; (2) Inclui motocompressores para refrigeração, eletrônica embarcada e partes e peças; e (3) Inclui autorrádios.

${ }^{14}$ Como bem observou Tavares (2001), os dados não levam em consideração a chamada eletrônica embarcada (componentes eletrônicos presentes em automóveis, bens de capital, etc.). Contudo, o valor da eletrônica embarcada representa fração relativamente pequena do total do valor dos componentes.

Revista de Ciências da Administração • v. II, n. 24, p. 69-I0I, maio/ago 2009 
No Brasil, o mercado informal, denominado de "mercado cinza", no setor de informática é bastante expressivo, sendo que alguns estudos produzidos pelo BNDES estimam que possa chegar a até $50 \%$ do mercado. Percebe-se, assim, que os agentes que ingressarem no mercado de semicondutores terão, como um dos desafios, que enfrentar um mercado segmentado. De todo modo, os consumidores do mercado informal podem representar também uma nova parcela de mercado a conquistar.

Atualmente, existem poucas empresas atuando no mercado brasileiro de semicondutores, sendo que elas atuam em certos nichos de mercado. Podese destacar: a Itautec-Philco, que atua principalmente na fase de back-end de memórias; e a Semikron, que atua na fabricação de semicondutores discretos. O valor estimado da fatia de mercado dessas empresas é de apenas US\$ 20 milhões (MELO, RIOS; GUTIERREZ, 2001).

Dado o dinamismo desse mercado e sua importância, há espaço para expansão das plantas de semicondutores em todos os níveis, visando as mais diversas aplicações.

A situação do complexo eletrônico brasileiro, com constantes déficits comerciais e tendência de aumento de demanda de componentes semicondutores por diversos segmentos industriais, possui caráter estratégico. Entretanto, a criação e o desenvolvimento de um parque produtivo, em um segmento que exige altíssimos investimentos e ambiente tecnológico avançado, dependem, fundamentalmente, além da participação do setor privado, do governo, no papel da indução e coordenação de diversas atividades orientadas para a formação de recursos humanos, criação de instituições de $\mathrm{P} \& \mathrm{D}$ e implementação de políticas de longo prazo favoráveis ao investimento, financiamento e desenvolvimento tecnológico - tal como foi feito pela coletividade junto ao setor petroquímico. Essas questões serão retomadas na próxima seção, referente à política industrial.

\section{Políticas Industriais Orientadas pela Indústria de semicondutores}

\subsection{Indústria Eletrônica no Brasil}

No Brasil, a indústria eletrônica surgiu em meados da década de 50, com alguns produtos de áudio e vídeo, por meio da produção de eletrônicos 
de consumo, montados com componentes importados e que só começaram (uma parte) a ser produzidos localmente na década seguinte, a partir da instalação da fábrica da Philco. Em 1968, o país se aventurou em algumas atividades de pesquisa iniciadas pela USP, com a criação de um Laboratório de Microeletrônica. A reserva de mercado para informática, que vigorou durante a década de 80, favoreceu a atuação de várias empresas nacionais, inclusive através da utilização de diversos componentes de fabricação nacional. A rigor, eram utilizados componentes disponíveis no país e componentes importados não produzidos internamente. Todavia, era sempre maciça a presença de tecnologia adquirida no exterior.

A difusão de produtos eletrônicos no mercado brasileiro ocorreu durante a década de 70 , havendo, no início da década de 80 , um número razoável de fabricantes de componentes eletrônicos. Nessa fase de implementação, a participação do governo foi incipiente, de sorte que as indústrias instalaram-se sem contar com incentivos públicos. Os incentivos existentes eram somente isenções de imposto de importação para os bens que tinham como destino as exportações. No setor de telecomunicações, destaca-se a criação do Centro de Pesquisa e Desenvolvimento em Telecomunicações (CPqD), que atuou no desenvolvimento de sistemas e equipamentos em tecnologia da informação. No setor de informática, destaca-se a formulação da Política Nacional de Informática (PNI), legitimada pela Lei de Informática (Lei n. 7.232/84), criando reserva de mercado para a indústria nacional e, também, alguns incentivos de cunho fiscal. A reserva de mercado levou à proteção da indústria nacional e, embora tenha dotado o país de certas capacitações na oferta de produtos e serviços, explica o relativo atraso tecnológico frente às indústrias estrangeiras (orientadas a exportação e às exigências do mercado externo).

\subsection{Abertura e Emergência da Política Industrial em Semicondutores}

A abertura comercial dos anos $90 \mathrm{fez}$ com que os setores do complexo eletrônico, incluindo o de componentes, estivessem entre os mais atingidos, de modo que a concorrência abrupta com produtos estrangeiros levou ao quase total desaparecimento da indústria nacional, excetuando-se algumas fábricas que atualmente operam em nichos de mercado. 
Em meio ao fraco desempenho da economia brasileira nas décadas de 80 e início de 90 e à necessidade de ajustamentos estruturais e Estado, passou-se a questionar as formas de atuação do governo. Com o argumento de que a atuação estatal poderia levar a distorções diversas, a corrente econômica menos intervencionista argumentava que a ação governamental conduz, em muitos casos, a perdas de eficiência. Contudo, ante a conquista (parcial) da estabilização, uma facção teórica mais desenvolvimentista ganhou força, apontando que a política industrial balizada pelas ações do governo pode corrigir e dinamizar certos mercados em que as ações dos produtores isolados são ineficientes - notadamente nos mercados mais associados a inovações e ao desenvolvimento tecnológico. Assim, a intervenção pública alocativa para o desenvolvimento de indústrias de alto teor tecnológico se justificaria pela existência de externalidades positivas, grau elevado de interesse público, necessidade de pesados investimentos numa perspectiva de longo prazo e retornos incertos, associados à emergência de uma base de conhecimentos (codificado e tácito) sólidos que envolvem a formação de recursos humanos altamente especializados. ${ }^{15}$ Nesse contexto surge a Política Industrial, Tecnológica e de Comércio Exterior - PITCE, em março de 2004, com o objetivo de aumentar a eficiência da estrutura produtiva da indústria nacional e a capacidade de inovação das empresas, visando a expansão das exportações e maior penetração do país no comércio internacional.

A função alocativa do governo se dará pela seleção de quatro setores prioritários (fármacos, software, bens de capital e semicondutores), que devem ser amparadas por medidas de apoio direto e indireto. O caráter vertical (setores específicos) é justificado devido ao peso crescente desses setores na balança comercial, além de serem setores estratégicos ao desenvolvimento moderno, com geração de externalidades positivas e difusão de Ciência, Tecnologia e Inovação - C\&T e I.

Dentre os 11 programas que constituem a PITCE, um merece destaque especial para este trabalho: Opções Estratégicas - Tecnologia da Informação/Semicondutores. Como concebido pelo governo, o programa visa fortalecer e desenvolver a indústria microeletrônica no Brasil, utilizando-se de instrumentos creditícios destinados à produção de microchips, além

\footnotetext{
${ }^{15}$ A função alocativa de governo está diretamente relacionada com os ideais de política industrial, que pode ser definida como: "A criação, implementação, coordenação e controle estratégico de instrumentos destinados a ampliar a capacidade produtiva e comercial da indústria, a fim de garantir condições concorrencias (SIC) sustentáveis nos mercados interno e externo" (CAMPANARIO; SILVA, 2004, p.14). Para Coutinho e Sarti (2004), esses instrumentos devem ser voltados para iniciativas horizontais (indústria como um todo) e verticais (setores específicos), visando ao aumento da competitividade e desenvolvimento de C\&T I.
} 
da criação de laboratórios voltados para P\&D em microeletrônica e nanotecnologia, capacitando o país com uma infraestrutura tecnológica nesse setor.

O Quadro 5 sumariza as principais medidas da PITCE orientadas ao desenvolvimento da indústria nacional de semicondutores, assim como algumas outras medidas que, apesar de não fazerem parte do programa de Opções Estratégicas-Semicondutores (OE-Semicondutores), gerarão externalidades positivas. De todas as medidas propostas pela PITCE, ao menos a terça parte refere-se direta ou indiretamente ao desenvolvimento de um parque industrial de semicondutores. De maneira geral, essas medidas pretendem incentivos fiscais (1 e 16); apoio financeiro (5 e 8); aumento do investimento em inovações (2, 4, 9, 11 e 15); e criação de infraestrutura $(3,5,6,7,10$ e 12), com forte relação com a indústria de semicondutores. O objetivo é a priorização da aquisição de máquinas e equipamentos, atração de investimentos externos e criação de laboratórios para desenvolvimento dessa indústria. Pode-se dizer que o desenvolvimento da indústria de semicondutores está baseado em três grandes programas: Programa Nacional de Microeletrônica, no Programa de Formação de Recursos Humanos e Programa de Incentivo à produção de chips. O Programa Nacional de Microeletrônica foi formulado num período anterior a PITCE, englobando também o Programa de Design Houses e de atração de empresas estrangeiras. O Programa de incentivo à produção de chips, ainda que disponibilize um volume pequeno de recursos, deve atuar em consonância com outras medidas para incentivar a capacitação tecnológica das empresas. Ao menos em termos explicitados, a orientação da PITCE para o aumento da exportação dos setores prioritários revela a tentativa de criação de vantagens comparativas dinâmicas, por meio da valorização da inovação focada na empresa como fator de aumento de produtividade e competitividade (Quadro 5). Nesse contexto, o Conselho Nacional de Desenvolvimento Industrial (CNDI) e a Agência Nacional de Desenvolvimento Industrial (ABDI) surgem da necessidade de articulação, coordenação e convergência da execução e acompanhamento dos diversos programas e medidas da PITCE. Como se percebe, a execução da PITCE ainda que focada no Ministério do Desenvolvimento, Indústria e Comércio Exterior (MDIC) e no Ministério da Ciência e Tecnologia (MCT), envolve ainda diversas outras instituições, gerando dificuldades de interrelacionamento e perda de eficiência. 


\begin{tabular}{|c|c|c|c|c|c|}
\hline $\mathbf{N}^{\circ}$ & Medida & O que é & Meta & Execução & $\begin{array}{l}\text { Importância para } \\
\text { o setor de } \\
\text { semicondutores }\end{array}$ \\
\hline \multicolumn{6}{|c|}{ OPÇÕES ESTRATÉGICAS - TECNOLOGIA DA INFORMAÇÃO/SEMICONDUTORES } \\
\hline 1 & $\begin{array}{l}\text { Regime Adua- } \\
\text { neiro Especial }\end{array}$ & $\begin{array}{l}\text { Inclusão no novo } \\
\text { RECOF. }\end{array}$ & $\begin{array}{l}\text { Agilizar o desemba- } \\
\text { raço aduaneiro do } \\
\text { setor. Em implanta- } \\
\text { ção pela Receita } \\
\text { Federal. }\end{array}$ & MF e MDIC & $\begin{array}{l}\text { Facilitar importação } \\
\text { de máquinas, equipa- } \\
\text { mentos e insumos. }\end{array}$ \\
\hline 2 & $\begin{array}{l}\text { Projeto de Lei } \\
\text { da Topografia } \\
\text { de Circuitos } \\
\text { Integrados }\end{array}$ & $\begin{array}{l}\text { Indicação de regime } \\
\text { de urgência para o } \\
\text { projeto de lei sobre } \\
\text { proteção da proprie- } \\
\text { dade intelectual de to- } \\
\text { pografias de circuito } \\
\text { integrado (chips). }\end{array}$ & $\begin{array}{l}\text { Incentivar o proces- } \\
\text { so de inovação no } \\
\text { setor de circuitos } \\
\text { integrados, que } \\
\text { compõem produtos } \\
\text { de alta tecnologia e } \\
\text { bens de consumo. }\end{array}$ & MDIC e MCT & $\begin{array}{l}\text { Garantir direitos de } \\
\text { propriedade intelectu- } \\
\text { al extremamente im- } \\
\text { portantes nas indús- } \\
\text { trias de alta tecnolo- } \\
\text { gia. }\end{array}$ \\
\hline 3 & $\begin{array}{l}\text { Laboratório } \\
\text { Nacional de } \\
\text { Tecnologia In- } \\
\text { dustrial }\end{array}$ & $\begin{array}{l}\text { Implantação de um la- } \\
\text { boratório nacional que } \\
\text { irá desenvolver proje- } \\
\text { tos e pesquisas em } \\
\text { micro e nanotecnologia } \\
\text { aplicadas a negócios, } \\
\text { em parceria com em- } \\
\text { presas. }\end{array}$ & $\begin{array}{l}\text { Dotar o país de } \\
\text { infraestrutura deci- } \\
\text { siva em tecnologia } \\
\text { industrial. }\end{array}$ & $\begin{array}{l}\text { Grupo de Tra- } \\
\text { balho de Semi- } \\
\text { condutores }\end{array}$ & $\begin{array}{l}\text { Criação de infraestru- } \\
\text { tura de pesquisa vi- } \\
\text { sando à fase de cria- } \\
\text { ção. }\end{array}$ \\
\hline 4 & $\begin{array}{l}\text { Programa de } \\
\text { Recursos } \mathrm{Hu}- \\
\text { manos }\end{array}$ & $\begin{array}{l}\text { Aumento e melhoria } \\
\text { da formação de re- } \\
\text { cursos humanos (mes- } \\
\text { tre e doutores) e pro- } \\
\text { jetistas na área de } \\
\text { microeletrônica, com } \\
\text { especial ênfase para } \\
\text { formação de recursos } \\
\text { humanos para o CT- } \\
\text { PIM (Manaus). }\end{array}$ & $\begin{array}{l}\text { Desenvolver a ca- } \\
\text { pacidade de inova- } \\
\text { ção das instituições } \\
\text { brasileiras. }\end{array}$ & $\begin{array}{l}\text { MCT, MDIC, } \\
\text { FINEP, CAPES, } \\
\text { CNPq }\end{array}$ & $\begin{array}{l}\text { O setor de semicondu- } \\
\text { tores é dependente de } \\
\text { recursos humanos es- } \\
\text { pecializados. }\end{array}$ \\
\hline 5 & $\begin{array}{l}\text { Incentivo à } \\
\text { produção de } \\
\text { chips }\end{array}$ & $\begin{array}{l}\text { Linha de crédito para } \\
\text { produção de chips com } \\
\text { recursos de } \mathrm{R} \$ 10 \mathrm{mi}- \\
\text { lhões e prazo de finan- } \\
\text { ciamento de } 18 \text { meses. }\end{array}$ & $\begin{array}{l}\text { Capacitar as em- } \\
\text { presas e laboratóri- } \\
\text { os para a produção } \\
\text { seriadara de } \\
\text { microchips. }\end{array}$ & FINEP & Fomentar produção. \\
\hline 6 & CEITEC & $\begin{array}{l}\text { Viabilizar a instalação } \\
\text { do Centro Gaúcho de } \\
\text { Prototipagem. }\end{array}$ & $\begin{array}{l}\text { Desenvolver a } \\
\text { prototipagem naci- } \\
\text { onal de chips. }\end{array}$ & MCT & Visa o design de chips. \\
\hline 7 & $\begin{array}{l}\text { Progra m a } \\
\text { Nacional de } \\
\text { Microeletrônica }\end{array}$ & $\begin{array}{l}\text { Programa que visa } \\
\text { fortalecer e desenvol- } \\
\text { ver a indústria micro- } \\
\text { eletrônica no Brasil. }\end{array}$ & $\begin{array}{l}\text { Desenvolver a in- } \\
\text { dústria microele- } \\
\text { trônica no Brasil. }\end{array}$ & MCT & $\begin{array}{l}\text { Foca na criação de de- } \\
\text { sign houses e parcerias } \\
\text { com empresas estran- } \\
\text { geiras. }\end{array}$ \\
\hline
\end{tabular}




\begin{tabular}{|c|c|c|c|c|c|}
\hline $\mathbf{N}^{\circ}$ & Medida & O que é & Meta & Execução & $\begin{array}{l}\text { Importância para } \\
\text { o setor de } \\
\text { semicondutores }\end{array}$ \\
\hline & & \multicolumn{4}{|c|}{ OUTROS PROGRAMAS } \\
\hline 8 & $\begin{array}{l}\text { Bens de capi- } \\
\text { tal sob enco- } \\
\text { menda }\end{array}$ & $\begin{array}{l}\text { Criação de uma linha } \\
\text { de financiamento } \\
\text { para bens de capital } \\
\text { por encomenda, ser- } \\
\text { viços de engenharia, } \\
\text { main contractor e turn } \\
\text { key. Até agora, não } \\
\text { havia nenhum tipo de } \\
\text { financiamento para } \\
\text { compra de bens de ca- } \\
\text { pital sob encomenda. }\end{array}$ & $\begin{array}{l}\text { Cobrir lacuna exis- } \\
\text { tente hoje no siste- } \\
\text { ma. O BNDES irá } \\
\text { financiar tanto o } \\
\text { comprador quanto } \\
\text { o fabricante, com } \\
\text { disponibilização de } \\
\mathrm{R} \$ 500 \text { milhões em } \\
\text { recursos em } 2004 .\end{array}$ & BNDES & $\begin{array}{l}\text { Facilitar aquisição de } \\
\text { bens de capital utiliza- } \\
\text { dos na produção de } \\
\text { d i s p o s i t i v o s } \\
\text { semicondutores. }\end{array}$ \\
\hline 9 & $\begin{array}{l}\text { Lei de Inova- } \\
\text { ção }\end{array}$ & $\begin{array}{l}\text { Nova lei de incentivo } \\
\text { à inovação que atua } \\
\text { na relação universida- } \\
\text { de institutos de pes- } \\
\text { quisa-empresas. Pos- } \\
\text { sibilita que as univer- } \\
\text { sidades, institutos de } \\
\text { pesquisa e empresas } \\
\text { fechem acordos de } \\
\text { parceria para criação } \\
\text { de novos produtos e } \\
\text { processos. }\end{array}$ & $\begin{array}{l}\text { Criar condições } \\
\text { para que a taxa de } \\
\text { investimento em } \\
\text { P\&D aumente nas } \\
\text { empresas, integrar } \\
\text { esforços de P\&D de } \\
\text { empresas e de uni- } \\
\text { versidades e institu- } \\
\text { tos de pesquisa. }\end{array}$ & MCT & $\begin{array}{l}\text { A parceria entre uni- } \\
\text { versidades e empresas } \\
\text { é uma das formas de } \\
\text { criação de novos pro- } \\
\text { dutos e processos de } \\
\text { produção. }\end{array}$ \\
\hline 10 & $\begin{array}{l}\text { Program a } \\
\text { Nacional de } \\
\text { Qualificação e } \\
\text { Modernização } \\
\text { dos Institutos } \\
\text { e Centros de } \\
\text { Pesquisa }\end{array}$ & $\begin{array}{l}\text { Modernizar } \\
\text { reestruturar os institu- } \\
\text { tos e centros de pes- } \\
\text { quisa a partir de um } \\
\text { novo conceito de ges- } \\
\text { tão e de áreas de es- } \\
\text { pecialização. }\end{array}$ & $\begin{array}{l}\text { Dotar o país de uma } \\
\text { infraestrutura de } \\
\text { pesquisa aplicada } \\
\text { capaz de sustentar o } \\
\text { processo de inova- } \\
\text { ção e capacitação } \\
\text { produtiva das em- } \\
\text { presas. }\end{array}$ & FINEP & $\begin{array}{l}\text { A criação de labora- } \\
\text { tórios e institutos de } \\
\text { pesquisas é de grande } \\
\text { importância nas fases } \\
\text { de imitação e de } \\
\text { internalização. }\end{array}$ \\
\hline
\end{tabular}

Quadro 5: Principais medidas da PITCE responsáveis pela criação e desenvolvimento do setor de semicondutores

Fonte: Elaborado pelos autores a partir de dados apresentados em BRASIL (2004). 


\begin{tabular}{|c|c|c|c|c|c|}
\hline $\mathbf{N}^{\circ}$ & Medida & O que é & Meta & Execução & $\begin{array}{l}\text { Importância para } \\
\text { o setor de semi- } \\
\text { condutores }\end{array}$ \\
\hline \multicolumn{6}{|c|}{ OUTROS PROGRAMAS } \\
\hline 11 & $\begin{array}{l}\text { Decreto } \mathrm{n}^{\circ} \\
4.928 \text { de Pes- } \\
\text { quisa \& De- } \\
\text { senvolvimento } \\
\text { e Certificação }\end{array}$ & $\begin{array}{l}\text { Decreto que incentiva } \\
\text { o processo de paten- } \\
\text { teamento e certifica- } \\
\text { ção ao possibilitar } \\
\text { que as empresas des- } \\
\text { contem as despesas } \\
\text { com depósitos de pa- } \\
\text { tente, certificação e } \\
\text { com Pesquisa e De- } \\
\text { senvolvimento (P \& } \\
\text { D) da Contribuição } \\
\text { Social sobre o lucro } \\
\text { Líquido (CSLL). As } \\
\text { despesas com depósi- } \\
\text { to de patente podem } \\
\text { ser abatidas em do- } \\
\text { bro. Em vigor desde } \\
23 / 12 / 03 \text {. }\end{array}$ & $\begin{array}{l}\text { Aumentar o núme- } \\
\text { ro de registro de } \\
\text { patentes no Brasil, } \\
\text { ampliando assim a } \\
\text { capacidade de ino- } \\
\text { vação do País. }\end{array}$ & MCT & $\begin{array}{l}\text { Facilita a criação de } \\
\text { patentes e investimen- } \\
\text { tos em P \& D. }\end{array}$ \\
\hline 12 & $\begin{array}{l}\text { Política Indus- } \\
\text { trial de Nano- } \\
\text { tecnologia }\end{array}$ & $\begin{array}{l}\text { Visa estruturar as } \\
\text { ações industriais do } \\
\text { setor. }\end{array}$ & $\begin{array}{l}\text { Desenvolver setor } \\
\text { de Nanotecnologia. }\end{array}$ & MDIC e MCT & $\begin{array}{l}\text { Criação de dispositi- } \\
\text { vos microeletrônicos } \\
\text { de dimensões extre- } \\
\text { mamente reduzidas. }\end{array}$ \\
\hline 13 & $\begin{array}{l}\text { Criação de } \\
\text { Conselho } \mathrm{Na}- \\
\text { cional de De- } \\
\text { senvolvimento } \\
\text { Industrial }\end{array}$ & $\begin{array}{l}\text { Criação de um con- } \\
\text { selho consultivo que } \\
\text { reúne ministros, em- } \\
\text { presários e trabalha- } \\
\text { dores para definir as } \\
\text { diretrizes de desenvol- } \\
\text { vimento industrial do } \\
\text { País. }\end{array}$ & $\begin{array}{l}\text { Orientar as estraté- } \\
\text { gias de desenvolvi- } \\
\text { mento e elaborar } \\
\text { planos e subsídios } \\
\text { para a PITCE. }\end{array}$ & $\mathrm{MDIC} / \mathrm{MCT}$ & $\begin{array}{l}\text { Coordenar e articular } \\
\text { os diversos programas } \\
\text { e medidas. }\end{array}$ \\
\hline 14 & $\begin{array}{l}\text { Criação da } \\
\text { Agência Bra- } \\
\text { sileira de De- } \\
\text { senvolvimento } \\
\text { Industrial }\end{array}$ & $\begin{array}{l}\text { Criação de uma agên- } \\
\text { cia de articulação e } \\
\text { execução da PITCE. }\end{array}$ & $\begin{array}{l}\text { Concentrar em um } \\
\text { só órgão as execu- } \\
\text { ções das ações pri- } \\
\text { oritárias da PITCE. }\end{array}$ & $\mathrm{MDIC} / \mathrm{MCT}$ & $\begin{array}{l}\text { Coordenar e articular } \\
\text { os diversos programas } \\
\text { e medidas. }\end{array}$ \\
\hline
\end{tabular}

Quadro 5: Principais medidas da PITCE responsáveis pela criação e desenvolvimento do setor de semicondutores

Fonte: Elaborado pelos autores a partir de dados apresentados em BRASIL (2004). 


\begin{tabular}{|c|c|c|c|c|c|}
\hline $\mathbf{N}^{\circ}$ & Medida & O que é & Meta & Execução & $\begin{array}{l}\text { Importância para } \\
\text { o setor de semi- } \\
\text { condutores }\end{array}$ \\
\hline \multicolumn{6}{|c|}{ OUTROS PROGRAMAS } \\
\hline 15 & $\begin{array}{l}\text { Sala Especial } \\
\text { de Atração de } \\
\text { Investimentos }\end{array}$ & $\begin{array}{l}\text { Grupo permanente } \\
\text { vinculado à Presidên- } \\
\text { cia (MDIC, MRE, MF, } \\
\text { MP, MME, MMA, } \\
\text { MCT, Turismo e Casa } \\
\text { Civil) destinado a cri- } \\
\text { ação de agenda de } \\
\text { investimentos setori- } \\
\text { al. Os investidores in- } \\
\text { teressados no país te- } \\
\text { rão como, de uma vez } \\
\text { só, falar com todos os } \\
\text { órgãos do governo. }\end{array}$ & $\begin{array}{l}\text { Facilitar e agilizar o } \\
\text { processo de atra- } \\
\text { ção de investimen- } \\
\text { tos para o país. }\end{array}$ & $\begin{array}{|lr|}\text { Presidência } & \text { da } \\
\text { República } & e \\
\text { MDIC } & \end{array}$ & $\begin{array}{l}\text { Investimentos estran- } \\
\text { geiros são de extrema } \\
\text { importância no de- } \\
\text { senvolvimento do se- } \\
\text { tor de semiconduto- } \\
\text { res. }\end{array}$ \\
\hline 16 & $\begin{array}{l}\text { Redução do } \\
\text { Imposto de } \\
\text { Importação } \\
\text { para máqui- } \\
\text { nas sem pro- } \\
\text { dução nacio- } \\
\text { nal }\end{array}$ & $\begin{array}{l}\text { Visa facilitar a impor- } \\
\text { tação de bens de ca- } \\
\text { pital sem similares no } \\
\text { Brasil por meio da } \\
\text { redução da alíquota } \\
\text { dos "ex-tarifários" de } \\
4 \% \text { para } 2 \% \text {, no caso } \\
\text { de haver produção em } \\
\text { algum país do Merco- } \\
\text { sul, e para } 0 \% \text { quan- } \\
\text { do não houver produ- } \\
\text { ção em nenhum país } \\
\text { o bloco. Em vigor des- } \\
\text { de } 19 \text { de fevereiro, } \\
\text { pela Resolução Ca- } \\
\text { mex }{ }^{\circ} 5 \text {. }\end{array}$ & $\begin{array}{l}\text { Todas as empresas } \\
\text { nacionais. }\end{array}$ & CAMEX & $\begin{array}{l}\text { Facilitar aquisição de } \\
\text { máquinas e equipa- } \\
\text { mentos utilizados na } \\
\text { produção de disposi- } \\
\text { tivos semicondutores. }\end{array}$ \\
\hline
\end{tabular}

Quadro 5: Principais medidas da PITCE responsáveis pela criação e desenvolvimento do setor de semicondutores

Fonte: Elaborado pelos autores a partir de dados apresentados em BRASIL (2004).

Uma discussão de estrema relevância está relacionada articulação de objetivos (macro, microeconômicos e setoriais) e o caráter das iniciativas levadas a cabo pelas diversas instituições governamentais. Isso se associa a seleção de critérios objetivos de acompanhamento, a efetiva avaliação de resultados em termos de seu caráter, clareza e progressividade de incentivos - que devem premiar as iniciativas de acordo com critérios previamente definidos. Com a introdução do Programa de Aceleração do Crescimento PAC, o governo federal alargou o horizonte das políticas de desenvolvimento, com uma estrutura mais articulada de seus componentes (Figura 3). 


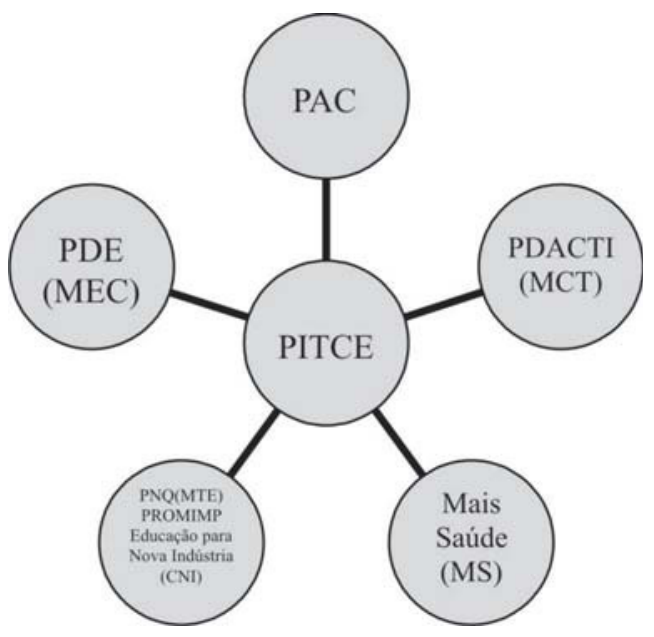

Figura 3: Marco de articulação de políticas da PITCE.

Fonte: Elaborado a partir de dados do Ministério do Planejamento.

Segundo a Abinee as medidas governamentais devem envolver questões de natureza fiscal e tributária, financeira, aduaneira, de capacitação tecnológica, de infraestrutura e de recursos humanos qualificados. Nessas respectivas linhas o governo tem proposto e anunciado ações na linha de desoneração tributária (eliminação de restrição de acesso aos incentivos do Programa na aquisição de máquinas e equipamentos usados - PADIS), apoio a capitalização de empresas com aportes do Banco Nacional de Desenvolvimento Econômico e Social - BNDES, apoio a pequenas e micro empresas PME's (por meio da estruturação, fortalecimento e capitalização de Fundos de Empresas Emergentes - FEEs e Fundos de Venture Capital visando a criação de design houses), promoção do investimento em inovação (por meio da Lei do Bem (Lei n $11.196 / 05)$, criação de centros tecnológicos e atração de investimentos estrangeiros (por meio da implantação do Programa de Atração de Investimentos Estrangeiros em Microeletrônica - PAIEM). No último caso o governos tem anunciado as seguintes ações: identificação de investidores potenciais, organização de missões de fomento para divulgação do mercado brasileiro e dos instrumentos de apoio existentes - apoio à estruturação de operações de investimento direto externo em microeletrônica (incluindo joint-ventures). Contudo, até o presente essas ações encontramse em fase de divulgação de vantagens do investimento no Brasil nesse setor dadas as características do mercado e incentivos oferecidos. ${ }^{16}$

${ }^{16}$ Maiores informações podem ser encontradas no documento da ABID < http://www.abdi.com.br/?q=node/1790> 


\subsection{A Experiência da Coreia do Sul}

Como foi visto na Seção 3, a participação de diversos países asiáticos na produção mundial de semicondutores aumentou sistematicamente nas últimas décadas. Esse fato foi resultado de uma política industrial de longo prazo instituída nesses países, visando ao aumento da produtividade e capacidade de exportação das indústrias (MELO, RIOS; GUTIERREZ, 2001). A Coreia do Sul representa um caso importante no estudo de desenvolvimento da indústria de semicondutores. A situação sul coreana, no início do programa de desenvolvimento industrial, era relativamente próxima à situação brasileira antes do processo de abertura da economia. A Coreia representava uma produção marginal de bens de alto conteúdo tecnológico, e a política industrial esteve voltada para setores específicos e para a busca do aumento de exportações. A estratégia coreana baseou-se em uma combinação de atração de investimentos estrangeiros, incentivos fiscais e financeiros, altos investimentos em $\mathrm{P} \& \mathrm{D}^{17}$ e formação de capacitação tecnológica para a conquista de competitividade internacional.

Byun (1994) identifica cinco fatores para o sucesso da política industrial sul coreana: (1) pesados investimentos em P\&D e na produção; (2) ênfase na produção de poucos bens (especialmente memórias); (3) criação de estratégias de difusão de conhecimento, incluindo processos de joint-ventures e instalação de instituições de pesquisa em outros países; (4) investimento na formação de recursos humanos e (5) papel fundamental do governo, através de subsídios, criação de infraestrutura de pesquisa, incentivos de pesquisa colaborativa e investimento em educação. De fato, o governo esteve presente em todos os fatores apontados acima, na medida em que priorizou o setor de semicondutores como um dos setores estratégicos e essenciais para o aumento da competitividade do parque produtivo coreano. Os investimentos do Estado em $\mathrm{P} \& \mathrm{D}$ e em qualificação de recursos humanos contribuíram para a formação de uma tecnologia industrial básica, $e$ incentivaram o setor privado a cooperar com os esforços de pesquisa.

Como forma de aumentar a eficiência produtiva, o governo coreano selecionou algumas empresas que seriam beneficiárias dos recursos disponíveis ${ }^{18}$. Essa estratégia estava focada na necessidade da concentração em alguns produtos considerados estratégicos e de grande valor e inserção no co-

${ }^{17}$ Os investimentos coreanos no período de 1983 a 1986 chegaram a US $\$ 1$ bilhão na produção e a US $\$ 180$ milhões em P\&D (Byun, 1994).
${ }^{18}$ Entre as grandes beneficiárias dos incentivos coreanos, destaca-se a Samsung. 
mércio internacional, notadamente equipamentos eletro e eletrônicos. Dessa maneira, os incentivos fornecidos pelo governo tinham como contrapartida das empresas o constante esforço de desenvolvimento de produtos eletro eletrônicos - inclusive utilizando-se de parcerias com empresas nacionais $e$ estrangeiras. Além disso, era exigido que as empresas beneficiadas atingissem uma determinada participação nas exportações.

Kim (1998) argumenta que o sucesso coreano está intrinsecamente correlacionado com o desenvolvimento dos Chaebols ${ }^{19}$ e do SNI. O papel do governo foi fundamental, desde a década de 70, no desenvolvimento das chamadas HCI (Heavy and Chemical Industry), pelo caráter de fortalecimento e concentração em empresas estratégicas, e na criação dos Chaebols. As políticas de substituição de importações, somadas às necessidades das grandes corporações expandirem sua área de atuação em outros segmentos, insentivou as Chaebols coreanas a entrarem no setor de eletrônicos, que representava, na ocasião, uma grande oportunidade de exportações.

Acompanhando o desenvolvimento do SNI coreano, o consequente desenvolvimento da indústria de semicondutores pode ser dividido em três fases: imitação, internalização e criação (LEE, 2005). A fase de imitação corresponde à necessidade de se importar tecnologia estrangeira $e$, por processos como a engenharia reversa, desenvolver tecnologias semelhantes. Nessa fase, a Coreia do Sul tinha disponível poucos Institutos de Pesquisa (IPs) e estes eram direcionados basicamente para testes e inspeções de materiais, tornando as atividades de $\mathrm{P} \& \mathrm{D}$ praticamente nulas. Também era pequena a quantidade de pesquisa realizada pelas empresas. Almejando contornar essa situação, enfatizou-se a política industrial e tecnológica coreana na criação de infraestrutura de pesquisa por meio de novos IPs e de investimentos em universidades, visando, também, à formação e capacitação de recursos humanos. Foi criado, ainda, um ambiente institucional favorável ao ingresso de investimentos estrangeiros.

O estágio da internalização caracteriza-se pela capacidade de desenvolvimento de produtos por meio de esforços locais. Desse modo, a política industrial coreana ampliou os investimentos em P\&D, visando ao desenvolvimento de tecnologias industriais de importância estratégica, inclusive com uma maior penetração de indústrias e universidades privadas (LEE, 2005). Nessa fase, o papel das Chaebols tornou-se mais expressivo como fator prin-

\footnotetext{
${ }^{19}$ Termo coreano para o conglomerado de diversas empresas, formando um arranjo em torno de uma empresa principal. As empresas tendem a ser controlados por uma única familia, tornando-se companhias gigantes. O termo é similar aos keiretsu, no Japão.
} 
cipal de desenvolvimento de novos produtos destinados à exportação e de criação de inovações. Para incentivar o aumento de P\&D interno, foram abolidas, nessa fase, diversas vantagens fiscais para aquisição de tecnologias estrangeiras (LEE, 2005; KIM, 1998).

Na fase de criação, a capacidade de introduzir produtos de alto conteúdo tecnológico é atingida. Esse corresponde ao estágio atual da indústria coreana. Embora a tecnologia de alguns segmentos, como o micrológico e ASICs (application-specific integrated circuit), esteja relativamente atrasada em relação aos países líderes, a participação da Coreia do Sul no fornecimento de patentes tecnológicas já é bastante expressiva. O país busca a consolidação do SNI por meio de uma maior sinergia entre as entidades acadêmicas, IPs públicos e privados e indústrias, com o fortalecimento de medidas de proteção à propriedade intelectual e com a internacionalização das empresas coreanas, através do estabelecimento delas em outros países.

As políticas de desenvolvimento da indústria de semicondutores da Coreia do Sul, calcadas em um programa de longo prazo, demonstraram ser bastante eficientes nas últimas décadas, tanto pela ampliação da produtividade e da capacidade produtiva, quanto pelo fortalecimento do SNI. Basta olhar para o aumento da participação das empresas coreanas no fornecimento de novos dispositivos e tecnologias para perceber que elas podem ser equiparadas com empresas de países desenvolvidos. Em suma, há fortes evidências de que as diversas políticas governamentais, desde que bem balizadas, podem ser eficientes para o desenvolvimento de indústrias de alta tecnologia.

\section{Considerações Finais e Recomendações}

O presente trabalho procurou dar indícios acerca da importância e papel da política industrial e tecnológica como fator fundamental para o desenvolvimento da indústria de semicondutores. O mercado mundial de semicondutores é bastante dinâmico e continua crescente, além de fazer parte dos setores mais intensivos em tecnologia e valor adicionado. Na produção e comércio de semicondutores, sobretudo memórias, a Coreia do Sul se destaca. Tal fato resulta da maturação de políticas de incentivo implementadas nas últimas décadas, consubstanciadas no desenvolvimento de condições favoráveis à inovação - como recurso à engenharia reversa -, formação de recursos humanos, apoio ao setor produtivo privado e formação de parceri- 
as. Como explicitado, o desenvolvimento da indústria de semicondutores pode ser divido em três fases: imitação, internalização e criação.

Em meio ao modelo nacional-desenvolvimentista, responsável por um dos mais rápidos e promissores processos de industrialização do pós-guerra, o Brasil ficou relativamente atrasado no desenvolvimento de setores de alto conteúdo tecnológico. A geração de capacidade produtiva era o foco por meio da introdução de tecnologia externa. A abertura comercial dos anos 1980 e 1990, com o fim da Lei do Similar e a eliminação de reserva de equipamentos de informática, faria com que os setores do complexo eletrônico, incluindo o de componentes, estivessem entre os mais atingidos, de modo que a concorrência abrupta com produtos estrangeiros levou ao quase total desaparecimento da indústria nacional, excetuando-se algumas fábricas que atualmente operam em nichos de mercado.

A abertura dos anos 1990 visava atrair investimentos e provocar um severo "choque de competitividade". Em meio à valorização da função estabilizadora, as políticas industriais seriam relegadas a um plano secundário. Recentemente, a Política Industrial, Tecnológica e de Comércio Exterior (PITCE) surgiu como meio de incentivar maior capacitação tecnológica em setores estratégicos. Pelo que se observa da leitura sistemática dos documentos de governo, as medidas planejadas englobam a valorização da inovação, a criação e aproveitamento da infraestrutura de $\mathrm{P} \& \mathrm{D}$, a formação $e$ capacitação de recursos humanos e a instituição de um ambiente favorável ao desenvolvimento industrial, com a valorização da inovação no interior da empresa em parceria com universidades e IPs.

O texto indica que as políticas orientadas ao desenvolvimento da indústria de semicondutores na PITCE geram condições para a maturidade das diversas fases seguidas pela Coreia do Sul, contudo, com grande ênfase nas fases de "imitação" e "internalização" (mais calcada na importação de máquinas e equipamentos) dessa indústria e alguma ênfase na fase de "criação" e desenvolvimento de tecnologia nacional. Como se observa nos documentos do governo, as medidas voltadas direta ou indiretamente para o desenvolvimento do setor de semicondutores priorizam a aquisição de máquinas e equipamentos, a atração de investimentos externos e a criação de laboratórios de pesquisa. De fato, para o desenvolvimento da indústria de semicondutores, algumas etapas adquirem importância fundamental. Inicialmente, faz-se necessária a atração de investimentos externos, na forma de contratos de transferência de tecnologia, a atração de uma indústria estrangeira de tecnologia de ponta e a formação de joint-ventures. Para isso, deve- 
se ter no país um ambiente político-institucional e econômico favorável e, principalmente, políticas de incentivos. Isso é importante por diversos motivos, entre eles, a necessidade de se aumentar a intensidade tecnológica do setor em um ritmo acelerado e ao mesmo tempo iniciar a produção de semicondutores no médio e longo prazos. Paralelamente, o investimento maciço na criação e capacitação de laboratórios e IPs, bem como na formação de recursos humanos é imprescindível para se criar capacitação em absorção e desenvolvimento de tecnologia própria. Deve-se observar também a criação de um ambiente que estimule uma maior interação entre as universidades e IPs com o setor produtivo, gerando uma aproximação entre a oferta e demanda de tecnologia. A criação de Design Houses é outra questão de ampla relevância, principalmente por possuir barreiras econômicas e tecnológicas mais amenas. A atuação dessas empresas conjuntamente com empresas estrangeiras é uma forma de desenvolver CIs para diversos segmentos, destacando-se semicondutores destinados a telecomunicações (devido à sua dinâmica crescente e às necessidades do país) e de uso específico.

A crescente demanda de semicondutores em setores como o automotivo, o agropecuário e o de eletrônicos de consumo, como a TV digital, pode significar oportunidades de negócio para essas empresas. De fato, os semicondutores de uso específico têm demonstrado ser o melhor caminho na produção nacional desses componentes. Tendo em vista o exposto, pelo menos do ponto de vista conceitual, a PITCE parece estar seguindo, segundo os programas e medidas apresentados pelo governo, o caminho correto. Pelo que se observa, as medidas planejadas pelo governo englobam a busca pelo desenvolvimento de inovações, a criação de infraestrutura de $\mathrm{P} \& \mathrm{D}$, a formação e a capacitação de recursos humanos e a instituição de um ambiente favorável ao desenvolvimento industrial. Entretanto, ressalta-se que a PITCE não apresenta explicitamente uma forma de atuação com o setor privado, nem demonstra claramente como vai ser o escopo e articulação entre as diversas instituições que irão operar as ações em semicondutores. Nesse caso, é prioritário definir claramente o papel da ABDI e do CNDI, dado que a articulação e a coordenação dos programas e medidas são necessárias para o bom desempenho da política setorial. Como foi demonstrado, as políticas industriais só têm sucesso se a indução de recursos para investimentos de se dá de forma articulada, de modo que medidas se concretizem nos resultados esperados.

Como aponta Carvalho (2006), o Brasil enfrenta vários obstáculos na trajetória de desenvolvimento da indústria de chips, entre eles: forma de atuação do governo (falhas de diagnóstico e planejamento, descontinuidade 
das políticas, mecanismos inadequados de financiamento e estratégia de desenvolvimento direcionada ao mercado doméstico); a carência de recursos humanos na área de projetos (reduzido número de profissionais habilitados em projetos de circuitos integrados); a fragilidade do arcabouço institucional (carência de órgãos de planejamento específicos para tratar do desenvolvimento e do monitoramento das necessidades do setor) e da infraestrutura de pesquisa; da ausência de mecanismos de transferência tecnológica; e de uma participação mais criteriosa do - investimento externo direto - IDE (ausência de mecanismos de transferência e assimilação tecnológica). Para contornar esses entraves e levando em conta as fases (imitação, internalização e criação) de desenvolvimento da indústria de semicondutores da Coreia do Sul o governo poderia focar em três vetores estratégicos: capacitação, articulação e focalização, conforme Quadro 6.

\begin{tabular}{|c|c|c|c|}
\hline \multirow[b]{2}{*}{ Vetores estratégicos } & \multicolumn{3}{|c|}{ Foco em termos das fases e de direcionadores de esforços. } \\
\hline & $\begin{array}{c}\text { Imitação } \\
\text { (introdução de } \\
\text { tecnologias difundi- } \\
\text { das) }\end{array}$ & $\begin{array}{c}\text { Internalização } \\
\text { (desenvolvimento da } \\
\text { produção e soluções } \\
\text { locais) }\end{array}$ & $\begin{array}{c}\text { Criação } \\
\text { (capacitar no desen- } \\
\text { volvimento de produ- } \\
\text { tos de alto conteúdo } \\
\text { tecnológico) }\end{array}$ \\
\hline $\begin{array}{l}\text { Capacitação } \\
\text { (investimento e } \\
\text { formação de parceri- } \\
\text { as de grande } \\
\text { alcance) }\end{array}$ & $\begin{array}{c}\text { Criação de estratégias } \\
\text { de difusão de conheci- } \\
\text { mento para desenvol- } \\
\text { vimento de soluções } \\
\text { locais aproveitando a } \\
\text { base produtiva local } \\
\text { existente }\end{array}$ & $\begin{array}{c}\text { Apoio ao incremento } \\
\text { da produção e atração } \\
\text { de investimento } \\
\text { externo direto em } \\
\text { parceria com empresas } \\
\text { locais }\end{array}$ & $\begin{array}{c}\text { Investimento em } \\
\text { infraestrutura de } \\
\text { pesquisa orientada à } \\
\text { novas aplicações em } \\
\text { tecnologias de médio } \\
\text { alto conteúdo } \\
\text { tecnológico }\end{array}$ \\
\hline $\begin{array}{l}\text { Articulação } \\
\text { (articulação de } \\
\text { políticas focalizadas } \\
\text { no plano setorial e } \\
\text { microeconômico) }\end{array}$ & $\begin{array}{c}\text { Criação e articulação } \\
\text { de incentivos e } \\
\text { contrapartidas bem } \\
\text { definidas junto aos } \\
\text { players em operação } \\
\text { em nível local e } \\
\text { internacional }\end{array}$ & $\begin{array}{c}\text { Promoção da articula- } \\
\text { ção de políticas } \\
\text { (telecomunicações, } \\
\text { industrial, comercial, } \\
\text { etc.) e mecanismos de } \\
\text { incentivo reduzindo os } \\
\text { custos de transação }\end{array}$ & $\begin{array}{l}\text { Focalizar esforços em } \\
\text { investimentos em P\&D } \\
\text { e na formação de } \\
\text { recursos humanos em } \\
\text { design e produção } \\
\text { junto às empresas }\end{array}$ \\
\hline $\begin{array}{l}\text { Focalização } \\
\text { (ajuste fino em } \\
\text { termos de foco e uso } \\
\text { de recursos escassos } \\
\text { em ativos estratégi- } \\
\text { cos) }\end{array}$ & $\begin{array}{c}\text { Incentivos à pesquisa } \\
\text { colaborativa e investi- } \\
\text { mento em educação } \\
\text { atrelados a extensão e } \\
\text { parcerias universidade/ } \\
\text { empresa }\end{array}$ & $\begin{array}{c}\text { Ênfase na produção de } \\
\text { poucos bens de caráter } \\
\text { estratégicos para } \\
\text { melhor desenvolvi- } \\
\text { mento das bases da } \\
\text { indústria }\end{array}$ & $\begin{array}{c}\text { Incentivos à formação } \\
\text { de joint-ventures e } \\
\text { instalação de institui- } \\
\text { ções de pesquisa em } \\
\text { parceria com outros } \\
\text { países }\end{array}$ \\
\hline
\end{tabular}

Quadro 6: Recomendações inspiradas no benchmark coreano.

Fonte: Elaborado pelos autores. 
Por fim, na linha da ampliação de estratégias microeconômicas baseadas na "imitação" e "internalização" o governo federal vinculou investimentos estrangeiros no setor como uma das contrapartidas durante as negociações para a adoção do padrão de TV Digital no país. Embora haja esforços do governo no sentido de atrelar o ingresso de grandes players da indústria de semicondutores há muitos desafios. Empresas do setor têm como estratégia introduzir apenas parte das etapas de fabricação de chips no Brasil o que, associados aos obstáculos apontados acima, tende a retardar o desenvolvimento da indústria nesse segmento.

\title{
Aspects of Industrial Policy to Support the Development of the Brazilian Semiconductor
}

\begin{abstract}
The achievement of macroeconomic stability tends to increase discussion about forms of intervention in microeconomic and sectorial policies. The Industrial, Technological and Foreign Trade Policy (PITCE), launched in early 2004, signaled that direction, electing four priority sectors: pharmaceuticals, capital goods, software and semiconductors. This paper analyzes the semiconductor industry in the national and international scales within selective industrial policy in fostering their development. From the characterization of the industry is done a benchmarking of the policies adopted by South Korea - a country that had similarities to Brazil, but has emerged as a major producer and exporter of high technology. The text indicates that policies directed toward the development of the semiconductor industry in the PITCE, create conditions for the maturity of the sector. However, it emphasizes the maturity phase of "imitation" (linked to the process of reverse engineering) and internalization (through the increase of the learning processes and domestic production), but little attention was reached in the breeding phase (getting its own technology) and the development of national technology. Guided by these vectors, the government pegged the deployment of Digital TV (High Definition TV - HDT) imposing the technological standards to be adopted as a bargain to build a semiconductor factory in Brazil by a foreign company.
\end{abstract}

Key-words: Industrial Policy. Technology. Electronic Complex. Semiconductors. PITCE. 


\section{Referências}

AMATO NETO, J. Relatório setorial final: semincondutores. 2004. Disponível em: <http://www.finep.gov.br/PortalDPP/relatorio_setorial_final/ relatorio_setorial_final_impressao.asp?lst_setor $=16>$. Acesso em: $28 \mathrm{mar}$. 2005.

. et al. Análise das condições de desenvolvimento da indústria brasileira de semicondutores: texto para discussão. In: Workshop Redes de Cooperação e Gestão do Conhecimento, 2, 2002, São Paulo. Anais... São Paulo: PROEPUSP, 2002.

BONELLI, R. Ensaios sobre política econômica e industrialização no Brasil. Rio de Janeiro: SENAI, 1996. 259p.

BRASIL. Presidência da República. Medidas de política industrial e de comércio exterior. Brasília: Casa Civil, 2004. 11p. Disponível em: <http:/ www.desenvolvimento.gov.br/arquivo/ascom/imprensa/ 20040331PlanoPoliticaIndustrial.pdf> . Acesso em: 12 fev. 2005.

BYUN, B. M. Growth and recent development of the korean semiconductor industry. Asian Survey, Berkeley, v. 34, n. 8, p. 706-720, Aug. 1994.

CARVALHO, P. Uma perspectiva para a indústria de semicondutores no Brasil: o desenvolvimento das "design houses". (Dissertação de Mestrado) Campinas: UNICAMP, 2006.

COMITÊ DAS ATIVIDADES DE PESQUISA E DESENVOLVIMENTO NA AMAZÔNIA. Microeletrônica e microsistemas. 2004. 23p. Disponível em: $<$ http://www.suframa.gov.br/download/documentos/ microeletronica_\%20versao2_maio2004.pdf>. Acesso em: 17 abr. 2005.

COUTINHO, L.; SARTI, F. A política industrial e a retomada do desenvolvimento. In: LAPLANE, M.; COUTINHO, L.; HIRATUKA, C. (Orgs.).

Internacionalização e desenvolvimento da indústria no Brasil. São Paulo: Fundação Editora da UNESP, 2004.

KIM, S. R. The korean system of innovation and the semiconductor industry: a governance perspective. Industrial and Corporate Change, Oxford, v. 7, n. 2, p. 275-309, june 1998. 
LEE, W. Y. O papel da política científica e tecnológica no desenvolvimento industrial da Coréia do Sul. In: KIM, L.; NELSON, R. R. (Orgs.). Tecnologia, aprendizado e inovação: as experiências das economias de industrialização recente. Campinas: UNICAMP, 2005. p. 365-394.

MELO, P. R. S., RIOS, E. C. S. D.; GUTIERREZ, R. M. V. Componentes eletrônicos: perspectivas para o Brasil. BNDES Setorial, Rio de Janeiro, n. 13, p. 3-64, mar. 2001.

NOGUEIRA, J. M.; MEDEIROS, M. A. A.; PEIXE, B. S. A. Propriedade industrial, inovação e adaptação tecnológica: oportunidades e desafios para a indústria brasileira. Disponível em: <http://www.desenvolvimento.gov.br/ arquivo/sti/publicacoes/futAmaDilOportunidades/futIndustria_05.pdf $>$. Acesso em: 21 mar. 2005.

SAI - SEMICONDUCTOR INDUSTRY ASSOCIATION. Estatísticas. Disponível em: <www.sia-online.org/cs/papers>. Acesso em: 19 jun. 2009.

SCHUMPETER, J. A. A teoria do desenvolvimento econômico. São Paulo: Abril Cultural, 1982.

SICSÚ, B. B. Desenvolvimento da indústria de componentes para o complexo eletrônico. In: FÓRUM NACIONAL, 14, 2002, Rio de Janeiro. Trabalhos Apresentados ... Rio de Janeiro: INAE, 2002.

STIGLITZ, J. E. Economics of the public sector. 3. ed. New York: W.W. Norton, 2000.

SWART, J. W. Estrutura de dispositivos semicondutores. Cap. 9. Disponível em: <http://www.ccs.unicamp.br/fee107/download/cap09.pdf>. Acesso em: 18 mar. 2005.

TAVARES, W. M. L. A indústria eletrônica no Brasil e seu impacto sobre a balança comercial. Brasília: Consultoria Legislativa, 2001. 20p. Disponível em: <http:/www2.camara.gov.br/publicacoes/ estnottec/tema4/pdf/ 108604.pdf>. Acesso em: 16 mar. 2005.

TURLEY, J. The essential guide to semiconductors. Upper Saddle River: Pearson Education, 2003.

VARIAN, H. R. Intermediate microeconomics: a modern approach. 6. ed. New York: W.W. Norton, 2002. 